\title{
Quando sei que eu sei? Quando sei que aprendo? Reflexões metacognitivas de estudantes de engenharia sobre Física
}

\section{When do I know that I know? When do I know that I learn? Metacognitive reflections of engineering students on Physics}

\author{
Keila Padilha de Oliveira Camargo de Lima' \\ Darinez Meneghello Passos ${ }^{1}$ \\ iD João Paulo Camargo de Lima²

\begin{abstract}
'Universidade Estadual de Londrina (UEL), Londrina, PR, Brasil. Autora Correspondente: keila.padilhalima@uel.br

Universidade Tecnológica Federal do Paraná (UTFPR), Londrina, PR, Brasil.
\end{abstract}

Resumo: Neste artigo trazemos os resultados de uma investigação que se dedicou a interpretar as percepções de estudantes do primeiro ano de um curso de Engenharia de uma universidade pública do estado do Paraná, sobre o saber e o aprender Física. Os estudantes responderam a um questionário com questões dissertativas que interpelavam a respeito de suas percepções relativas ao aprender e saber. Com base nas respostas dos estudantes e tomando os procedimentos da Análise de Conteúdo, foram observadas descrições das relações com o saber em três dimensões: epistêmicas, pessoais e sociais, assumidas por categorias a priori para a organização dos registros. Os movimentos analíticos permitiram evidenciar unidades de sentido e identificar verbos que caracterizassem as percepções dos estudantes em relação ao saber e ao aprender Física. Os resultados apontaram para o sentido de saber e de aprender relacionado com: prática/aplicação, processo de reflexão e dúvida em relação aos conteúdos de Física.

Palavras-chave: Metacognição; Processo de ensino e aprendizagem; Ensino de física.

Abstract: In this article, we present the results of an investigation dedicated to interpreting the perceptions of first-year Engineering students at a public university in Paraná state about knowing and learning Physics. Students answered a questionnaire with essay questions about their perceptions about learning and knowing. Based on the students' answers and Content Analysis procedures, the descriptions of their relationships with knowledge were observed in three domains: epistemic, personal, and social, which had been assumed by a priori categories for the organization of records. The analytical movements allowed us to reveal units of meaning, as well as to identify verbs that characterized the students' perceptions regarding knowledge and learning of Physics. The results pointed to the meanings of knowing and learning related to: practice/application, the process of reflection, and doubt regarding Physics content.

Keywords: Metacognition; Teaching and learning process; Physics teaching.

Recebido em: 02/11/2020

Aprovado em: 06/09/2021 


\section{Introdução}

O aprender é considerado um fenômeno da relação de quem aprende (aprendiz) com o mundo, por meio das interações, das relações, sendo que esse fenômeno possui um sentido de abertura à renovação, a uma busca, "[...] uma necessidade de indagação: por que, para que e o que se busca" (CORRÊA; PASSOS; ARRUDA, 2018, p. 518).

$O$ entendimento a respeito do aprender e do conceito de aprendizagem é hoje constituído e fundamentado em um amplo conjunto de abordagens, referenciais teóricos e teorias (ILLERIS, 2013). Para Charlot $(2000,2005)$, o aprender se origina de uma necessidade do ser humano, uma obrigação de aprender, pois para o autor o ser humano só pode tornar-se, constituir-se aprendendo, apropriando-se do mundo, a partir de uma relação com o mundo. Ainda, dentro destes pressupostos, com base na relação com o saber de Charlot $(2000,2005)$, aprender é um acontecimento, por meio de um movimento interior ao ser humano, "[...] que não pode existir sem o exterior de forma recíproca" (LIMA et al., 2015, p. 873).

Portanto, "ensinar é uma ação que tem origem externa ao sujeito, mas só pode ter êxito se encontrar um movimento interno ao sujeito" (LIMA et al., 2015, p. 873). Nesse mesmo caminho argumentativo, Illeris (2013) aponta condições internas e externas relacionadas à aprendizagem. Sobre as condições internas de aprendizagem, o autor refere-se a "características do aprendiz que influenciam as possibilidades de aprendizagem" (ILLERIS, 2013, p. 27). Diante destes apontamentos em relação à aprendizagem e ao aprender, tomamos as reflexões de Passos, Corrêa e Arruda (2017, p. 177) sobre o aprendizado, quando indicam que: "[...] ao estudar e estar consciente de como se conseguiu aprender determinados conteúdos, reconhecendo os fatores que corroboram e os que dificultam certa aprendizagem é que se constroem caminhos para a apropriação do próprio aprendizado".

Este processo de estar consciente sobre o que se aprende está no cerne das relações entre a aprendizagem e a metacognição. Nas palavras de Corrêa, Passos e Arruda (2018, p. 522), em uma reprodução de Peterson, Baker e McGaw (2010, p. 204), a palavra metacognição significa "pensar sobre o pensamento". Adicionado a isso, podemos observar o que nos traz Flavell (1976, p. 232) sobre a metacognição, ao descrever que "Metacognição refere-se ao conhecimento de alguém sobre os próprios processos e produtos cognitivos, ou qualquer coisa que os relaciona".

Considerando essas constatações a respeito da relação com o saber e com o aprender, e o processo metacognitivo envolvido nessas situações, neste artigo apresentamos os resultados de uma investigação que se dedicou a interpretar as percepções de estudantes de Engenharia sobre o saber e o aprender Física, quando eles participaram de uma atividade reflexiva proposta durante a aula de uma disciplina introdutória de Física. Nesta ocasião os estudantes foram convidados a responder a um questionário referente às seguintes questões: Quando sei que eu sei [Física]? Quando sei que aprendo [Física]?

Para interpretarmos os dados coletados inspiramo-nos nos significantes presentes na coluna 2 da Matriz do Estudante M(E) (ARRUDA; BENICIO; PASSOS, 2017), que se refere ao pensamento do estudante sobre seu próprio saber e sua própria aprendizagem. A Matriz do Estudante $M(E)$ refere-se a um instrumento para analisar as 
percepções dos estudantes em relação ao conteúdo, à aprendizagem e ao ensino em sala de aula, vinculados às Dimensões epistêmicas, pessoais e sociais com o saber e, por conseguinte, com o aprender. Os significantes presentes na coluna 2 da $M(E)$ dizem respeito aos pensamentos (epistêmicos), aos sentidos (pessoais) e aos valores (sociais) atribuídos pelo estudante em relação aos saberes e sua própria aprendizagem. Por esse motivo, as respostas registradas por eles foram analisadas a partir das descrições das relações epistêmicas, pessoais e sociais com o saber, presentes nos inscritos de Arruda, Lima e Passos (2011), o que nos levou, em resumo, ao seguinte desfecho: os registros apresentados pelos estudantes nesse processo, que consideramos ser um processo de reflexão metacognitiva, incidiram com maior frequência nas relações epistêmicas com o saber, seguido das relações pessoais e das relações sociais.

Todo esse processo (seus desdobramentos e inferências) foi organizado neste artigo da seguinte forma: na próxima seção trouxemos a fundamentação teórica, em que esclarecemos sobre alguns conceitos relativos à relação com o saber e o aprender, além de nossos posicionamentos inspirados na metacognição; na continuidade, descrevemos detalhes dos procedimentos metodológicos, exemplos relacionados aos dados (pois a completude de sua apresentação torna-se inviável em um artigo), os movimentos analíticos e, para encerrar, diversas discussões e conclusões que emergiram durante a investigação.

\section{Fundamentação teórica: alguns esclarecimentos}

A utilização do pensamento metacognitivo tem sido situada na literatura como uma das mais proeminentes estratégias de aprendizagem, com resultados significativos apontando para uma melhoria na eficácia dos processos educacionais (ROSA; GHIGGI, 2018; ROSA; VILLAGRÁ, 2018; ROSA; RIBEIRO; ROSA, 2018).

A metacognição, em geral, tem sido referida, como já indicado, ao "pensar sobre o pensamento", e aqui complementamos com: "pensar sobre o pensar" ou a "cognição da cognição" (CORRÊA; PASSOS; ARRUDA, 2018; ROSA; RIBEIRO; ROSA, 2018).

Pesquisadores afirmam que parece não haver consenso a respeito da definição e do conceito referente ao termo metacognição, todavia a maioria dos estudos converge para as perspectivas apresentadas por John Hurley Flavell (FLAVELL, 1976, 1979; ROSA; RIBEIRO; ROSA, 2018).

Corrêa et al. (2020) assumem a definição do termo metacognição descrita por Flavell (1979) como:

\footnotetext{
Uma consciência de como se aprende; consciência de quando se entende ou não uma proposta; conhecimento de como usar a informação disponível para alcançar uma aprendizagem; capacidade em julgar as demandas cognitivas de uma tarefa específica; conhecimento de que estratégias usar para quais finalidades e avaliação do progresso da própria pessoa durante e após o desempenho na realização de uma tarefa. (CORRÊA et al., 2020, p. 9).
}

Esses mesmos autores complementam que, a partir das ideias de Flavell (1976), vários teóricos passaram a apresentar uma conceituação e definições sobre o termo metacognição, entre eles: Baker e Brown (1984 apud CORRÊA et al., 2020, p. 9) apontaram que a metacognição é a "[...] capacidade de usar mecanismos de autorregulação para assegurar a conclusão bem-sucedida de uma tarefa, ou seja, ter consciência de que, para 
executar uma tarefa de forma eficaz, é necessário utilizar de recursos, habilidades e estratégias". Para Andretta et al. (2010), a metacognição não é apenas um conhecimento sobre a cognição, mas uma etapa do processamento de nível elevado, que é adquirida e desenvolvida pela experiência e pelo conhecimento específico armazenado. Diante dessas exposições, pode-se considerar que as informações armazenadas pelo sujeito também controlam o conhecimento referente às ações sólidas que ele irá realizar no mundo.

Dentro desses pressupostos descritos anteriormente, Baker (2010) indica que o termo metacognição significa literalmente "pensar sobre o pensamento". Seus estudos ampliam os conceitos iniciados por Flavell (1976), apontando que:

\begin{abstract}
A Metacognição está interessada na capacidade de reflexão sobre o nosso próprio pensamento, e em um contexto acadêmico ela inclui o conhecimento sobre nós mesmos como aprendizes, sobre os aspectos da tarefa, e sobre o uso da estratégia. Metacognição também envolve a autorregulação de nossos próprios esforços cognitivos, incluindo planejar as nossas ações, verificar os resultados dos nossos esforços, avaliar o nosso progresso, corrigir as dificuldades que surgem, testar e revisar as nossas estratégias para a aprendizagem. (BAKER, 2010, p. 204, tradução nossa).
\end{abstract}

Ainda no sentido de ampliar o conceito, Efklides (2008) apresenta a metacognição de forma multifacetada. A autora aponta que o processo metacognitivo pode envolver também a emoção e a Dimensão social. A emoção se conecta à cognição por meio das experiências cognitivas. Da mesma maneira, as intervenções que focam em metacognição explícita, "[...] por serem medidas por outras pessoas incorporam o nível social, ou seja, a ação no mundo, bem como os níveis conscientes e inconscientes do funcionamento da metacognição" (CORREA et al., 2021, p. 128).

Em se tratando dos estudos a respeito da metacognição associados ao Ensino de Ciências, tem-se observado um aumento de publicações nessa temática e, embora evidenciado esse crescente interesse, pesquisadores têm apontado a necessidade de ampliar as pesquisas nessa área de investigação (AVARGIL; LAVI; DORI, 2018; VEENMAN, 2012; ZOHAR; BARZILAI, 2013).

Em recente publicação alusiva aos 50 anos do artigo de John Hurley Flavell, que deu origem ao tema metacognição, Rosa et al. (2021) indicam possíveis cenários e perspectivas das pesquisas em metacognição no Ensino de Ciências. Segundo os autores, vários estudos têm revelado benefícios e avanços em relação à aprendizagem dos estudantes, principalmente os estudos que associam a metacognição a situações didáticas. Dentre as pesquisas, os resultados tidos como mais promissores são os estudos que apontam a possibilidade e a necessidade de integrar às disciplinas curriculares situações que possam agenciar a ativação do pensamento metacognitivo. As investigações que compõem esses resultados são direcionadas a avaliar a metacognição de uma forma mais geral, ou seja, uma reflexão metacognitiva. Dentro desta característica, ainda de acordo com os autores, as pesquisas revelam melhoria em vários aspectos como: compreensão dos conceitos e fenômenos; oportunizar o desenvolvimento do pensamento crítico; motivação para aprender; autoconfiança do aprendiz; aumento da capacidade de resolução de problemas; melhoria na leitura de textos científicos; análise da argumentação de estudantes em atividades de Biologia e estabelecimento de categorias metacognitivas a partir de entrevistas com estudantes de Ensino Médio (ROSA et al., 2021). 
Ao estabelecer categorias metacognitivas a partir de entrevistas com estudantes, Corrêa, Passos e Arruda (2018) concluíram, após analisar as percepções dos mesmos a respeito do próprio processo de aprendizagem, que os sentimentos e os valores compõem o processo metacognitivo. Dessa forma, os autores apresentam as categorias metacognitivas: epistêmicas, pessoais e sociais.

Neste sentido, os autores mencionados anteriormente interpretam e identificam o conjunto de processos metacognitivos em termos de Dimensões epistêmicas, pessoais e sociais nas relações com o saber estabelecidas pelo indivíduo, integrando, dessa maneira, os conceitos de metacognição e de relação com o saber. Movimento semelhante é o que consideramos no processo investigativo deste artigo.

Complementando nossos posicionamentos, trazemos agora o que compreendemos e assumimos por relação com o saber, destacando que a relação com o saber é definida, fundamentalmente, como "uma forma da relação com o mundo" (CHARLOT, 2000, p. 77). Um mundo em que eu me encontro como um ser humano portador e movido por meus desejos, ocupando uma posição em um espaço social e dotado de uma história particular que define minha singularidade e maneira de dar sentido a esse mundo (CHARLOT, 2000). Ainda, segundo o autor, a relação com o saber é uma relação com o mundo, com o outro e consigo mesmo, e toda a relação do aprender e do saber é uma relação com o mundo em que o sujeito exerce uma atividade relacionada à sua trajetória. Uma relação com o outro no sentido de comunidade, eu aprendo com o outro, e a relação consigo mesmo de um sujeito que aprende com ele mesmo, em referência à construção da imagem de si mesmo (CHARLOT, 2000).

Charlot (2001) aponta que a questão do aprender é mais ampla que a relação com o saber. Aprender não é somente aprender um saber, é também aprender alguma atividade, bem como formas relacionais, ou seja, pode-se aprender a se relacionar. O autor também destaca que a relação com o saber pode ser descrita como relações epistêmicas, identitárias e sociais.

Em uma adaptação das definições a respeito das relações epistêmica, de identidade e social com o saber (CHARLOT, 2000), Arruda, Lima e Passos (2011) apontam descrições de relações epistêmicas, pessoais e sociais com o saber, conforme especificado no quadro 1.

Quadro 1 - Relações epistêmicas, pessoais e sociais com o saber

\begin{tabular}{|l|l|}
\hline Relações com o Saber & \multicolumn{1}{c|}{ Descrição } \\
\hline (A) Relação Epistêmica & $\begin{array}{l}\text { A relação epistêmica com o saber: diz respeito à relação com o saber enquanto um objeto do } \\
\text { mundo a ser apropriado e compreendido; um saber dotado de objetividade, consistência e } \\
\text { estrutura independentes; um saber "existente em si mesmo", "depositado em objetos, locais e } \\
\text { pessoas" e imerso em um "universo de saberes distinto do mundo da ação, das percepções e das } \\
\text { emoções" (CHARLOT, 2000, p. 69). }\end{array}$ \\
\hline (B) Relação Pessoal & $\begin{array}{l}\text { A relação pessoal com o saber: diz respeito à "relação de identidade com o saber"; o saber } \\
\text { enquanto objeto que faz sentido, que é parte da história pessoal do sujeito, de sua vida e de } \\
\text { suas expectativas (CHARLOT, 2000, p. 72); é o saber enquanto objeto de desejo, de interesse; o } \\
\text { saber que o sujeito "gosta" e que o faz mobilizar-se à sua procura. }\end{array}$ \\
\hline (C) Relação Social & $\begin{array}{l}\text { A relação social com o saber: diz respeito ao fato de que o sujeito nasce inscrito em um espaço } \\
\text { social, ocupando uma posição social objetiva, que lhe definem o contexto inicial em que ele vai } \\
\text { se relacionar com o saber; nesse meio o saber possui valores dados pela comunidade em que } \\
\text { o sujeito vive, recebendo o impacto das expectativas e aspirações de outros em relação a ele } \\
\text { (CHARLOT, 2000, p. 73). }\end{array}$ \\
\hline
\end{tabular}

Fonte: Arruda, Lima e Passos (2011, p. 145). 
Cabe lembrar que, para o desenvolvimento desta pesquisa, a descrição das relações epistêmicas, pessoais e sociais com o saber de Arruda, Lima e Passos (2011) do quadro 1, foram utilizadas como categorias a priori para a análise dos registros apresentados pelos estudantes de Engenharia que participaram da proposta investigativa.

\section{Procedimentos metodológicos}

Assumimos esta pesquisa como de cunho qualitativo, pelo fato de garantir caminhos transparentes e capazes de revelar em sua complexidade os dados obtidos, possibilitando uma forma de análise coesa, estruturada, coerente e flexível. Segundo Flick (2009, p. 23):

[...] aspectos essenciais da pesquisa qualitativa consistem na escolha adequada de métodos e teorias convenientes; no reconhecimento e na análise de diferentes perspectivas; nas reflexões dos pesquisadores a respeito de suas pesquisas como parte do processo de produção de conhecimento; e na variedade de abordagens e métodos.

Como indicado anteriormente, coletamos os dados por meio de questionários aplicados a estudantes (15 ao todo) do primeiro ano de um curso de Engenharia de uma Universidade Federal do estado do Paraná. Tais questionários ${ }^{1}$ foram compostos de duas questões dissertativas que compõem o título do artigo: Quando sei que eu sei? Quando sei que aprendo? Os estudantes responderam ao questionário durante o desenvolvimento de uma atividade reflexiva. A atividade reflexiva proposta foi organizada e desenvolvida em dois momentos. Em um primeiro momento realizou-se o feedback aos estudantes de forma individual, ou em grupo, do conjunto de atividades e avaliações realizadas até o momento. Esse primeiro momento proporcionou aos estudantes um momento de reflexão, no qual puderam verbalizar suas percepções a respeito das atividades e avaliações desenvolvidas na disciplina de Física, manifestando dessa forma suas dúvidas, compreensões, sentimentos e visões. Em um segundo momento foi proposto um questionário com as duas questões, com o objetivo de proporcionar aos estudantes um momento de reflexão sobre o próprio aprendizado na disciplina de Física.

Os dados obtidos, a partir dos registros às respostas das questões, foram analisados à luz da Análise de Conteúdo (AC). Bardin (2011) projetou para tais procedimentos três fases: a pré-análise, a exploração do material, o tratamento dos resultados, a inferência e a interpretação, definidas conforme destacado na continuidade.

A fase de pré-exploração e/ou pré-análise é um movimento marcado pela 'leitura flutuante', em que o pesquisador se familiariza com o documento, escolhe e organiza o material de pesquisa. Nele acontece uma preparação do material, que tem como movimento posterior permitir a codificação e a categorização dos recortes para preparação do corpus; seria como estar projetando um futuro, para a análise,

'A coleta das informações esteve amparada por um projeto submetido à Plataforma Brasil, que foi aprovado pelo Comitê de Ética da instituição de Ensino Superior em que estávamos vinculados na ocasião, tendo os seguintes CEP: 3045604 e CAAE: 57663716.9.0000.5231. 
com o presente sob sua observação. Consideramos como corpus, "[...] o conjunto dos documentos tidos em conta para serem submetidos aos procedimentos analíticos" (BARDIN, 2011, p. 126).

Na segunda fase tem-se a exploração do material, em que acontece a codificação, a classificação e a categorização (proposições interpretativas básicas nesta fase). Nela o pesquisador define seus critérios para a construção das categorias, propiciadas pela identificação das unidades de registro.

Na terceira, e última fase, ocorre a análise (em profundidade) do corpus, que culmina no tratamento dos resultados para a elaboração de uma comunicação dos achados, permeada por uma análise reflexiva e crítica do pesquisador.

No que diz respeito aos pormenores organizacionais esclarecemos que: primeiramente, transcrevemos todos os questionários respondidos pelos estudantes e, posteriormente, fragmentamos essas manifestações em função dos objetivos de pesquisa.

Na sequência, os estudantes receberam a codificação em numeração contínua, denominados por E1, E2, E3 e, sucessivamente, até E15; seus registros foram codificados por R1, R2 até R45. Para a apresentação neste artigo, os fragmentos das falas dos estudantes foram sinalizados pela codificação referente ao estudante e, em seguida, pela codificação do registro. Trazemos um exemplo: E5-R13, estudante E5 e registro R13.

Durante a exploração do material foi possível identificar unidades de sentido, seguindo os seguintes critérios apontados por Bardin (2011, p. 147): "lexical" (classificação das palavras segundo o seu sentido, com emparelhamento dos sinônimos e dos sentidos próximos) e "sintática" (os verbos e os adjetivos). Desse processo, foram evidenciadas 19 unidades de sentidos organizadas no quadro 3.

Cabe esclarecer que até chegarmos a esta organização foram realizados três movimentos: no primeiro, buscamos identificar nos 45 registros as Dimensões epistêmicas, pessoais e sociais, assumidas a priori; no segundo, estabelecemos critérios para a identificação das unidades de sentido, considerando um posicionamento lexical e sintático; por fim, no terceiro movimento, procuramos os verbos de ação descritos pelos estudantes, presentes nas unidades de sentido e que, por conseguinte, estavam integrados a uma das dimensões da relação com o saber e o aprender.

\section{Apresentação, organização e análise dos dados}

Para a apresentação, a organização e a análise dos dados, fizemos uso de algumas formas descritivas: quadros e gráficos, sendo que, juntamente a cada um desses elementos, seguem comentários elaborados a partir dos movimentos interpretativos realizados.

Os registros recebidos dos estudantes foram numerados de 1 a 45, como já mencionado. Selecionamos alguns exemplos e inserimos no quadro 2, para elucidar o movimento que consideramos na acomodação as categorias a priori. Indicamos na coluna dois deste quadro, no qual temos trechos dos registros, pelo fato de muitos deles serem longos, por isso optamos por selecionar 'partes' representativas (a nosso ver) da categoria em que o registro foi acomodado. 
Quadro 2 - Exemplos de registros² referentes às categorias epistêmica, pessoal e social

\begin{tabular}{|c|c|}
\hline Categorias & Trechos dos registros dos estudantes \\
\hline Epistêmica & $\begin{array}{l}\text { (E1-R1) Quando eu debato }{ }^{3} \text { e crio opiniões sobre aquilo que sei. } \\
\text { (E1-R2) Assim que eu obtenho resultado daquilo que estudei. } \\
\text { (E2-R4) Não é tão simples e nem tão fácil de alguém falar que sabe física. O máximo que eu posso falar é } \\
\text { que eu entendo um pouco de algumas áreas de Física, e sei disso, pois estudei e sei que eu sei, pois se eu } \\
\text { parar para refletir consigo mesmo saber o assunto, eu recordo o que aprendi, não claramente, mas lembro. } \\
\text { (E2-R6) Quando a maior parte dos exercícios fica fácil e quando a parte teórica está clara em minha cabeça. } \\
\text { (E5-R13) Eu sei que sei física quando vejo alguma coisa acontecendo e quando vejo algo prático que envolva } \\
\text { conceitos físicos e consigo dizer o porquê tal coisa acontece de tal forma e é da maneira que é. }\end{array}$ \\
\hline Pessoal & $\begin{array}{l}\text { (E2-R5) Quando até mesmo sem gostar do assunto que está sendo aprendido, me esforço em absorver } \\
\text { o máximo de informação de quem sabe. Com isso você aprendeu, mas para dizer que sei, devo procurar } \\
\text { aprender sozinho. } \\
\text { (E6-R17) Para aprender algo, deve-se primeiramente almejar o conhecimento que se deseja obter. Após } \\
\text { estar movido de vontade, deve-se estudar periodicamente voltando total atenção à matéria no momento } \\
\text { de estudar. Por fim, só aprende com o hábito de estudo. } \\
\text { (E7-R19) Na verdade, eu nunca sei quando eu sei devido à insegurança de transmitir um falso conhecimento } \\
\text { ou ser menosprezado por outrem que supostamente sabe mais do que eu; eu nunca posso ter a certeza sobre } \\
\text { o meu conhecimento, deixando que mesmo a verdade aparente absoluta tenha um princípio de dúvida. } \\
\text { (E8-R23) Quando dúvidas aparecem e procuro maneiras de resolvê-las, ou seja, é quando o estudo, } \\
\text { entendimento, dúvida, prática e esforço. } \\
\text { (E11-R32) Tem um provérbio que explica isso, escuto e esqueço, vejo e lembro, faço e aprendo. Ao pôr em } \\
\text { prática o aprendizado ele irá se concretizar. }\end{array}$ \\
\hline Social & $\begin{array}{l}\text { (E6-R18) Quando se sabe bem a matéria estudada, a pessoa consegue transmitir esse conhecimento a outro } \\
\text { de forma muito mais fácil, aquele que não detém o conhecimento necessário. } \\
\text { (E10-R29) Depois de executar ação várias vezes, de entender os conceitos envolvidos, fazer exercício, discutir } \\
\text { o assunto com colegas, se eu conseguirei explicar para alguém o assunto, de forma que eu consiga transmitir } \\
\text { o que eu aprendi, aí sim saberei que eu aprendi o assunto. } \\
\text { (E11-R33) Eu sei que eu aprendo quando consigo pôr em prática meu aprendizado, e a partir daí posso } \\
\text { passar o que aprendi para outras pessoas. } \\
\text { (E13-R39) Quando eu consigo colocar em prática aquilo que aprendi de forma coerente e correta, expondo } \\
\text { a ideia ou a situação como forma de ensino para outras pessoas. } \\
\text { (E12-R35) Eu aprendo quando sou forçada a aprender para ensinar os outros, pois, e quando faço uma } \\
\text { reflexão acerca do que está sendo apresentado a mim, de forma crítica, quando penso nas possíveis dúvidas } \\
\text { e questionamentos que podem ser feitos a mim. }\end{array}$ \\
\hline
\end{tabular}

Fonte: elaborado pelos autores.

A organização de todos os registros proporcionou a elaboração do gráfico 1, exposto a seguir.

\section{Gráfico 1 - Distribuição dos registros nas três Dimensões ${ }^{4}$}

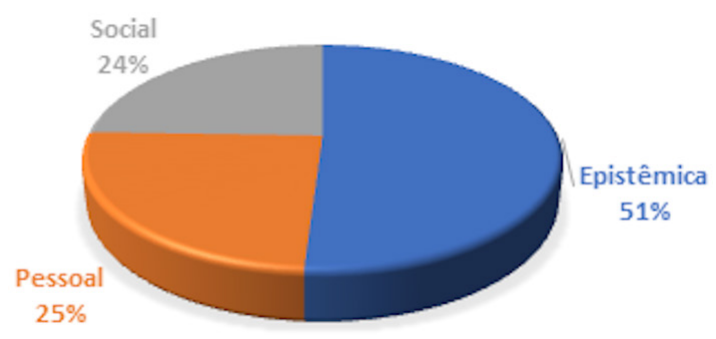

Fonte: elaborado pelos autores.

\footnotetext{
${ }^{2}$ Os registros dos estudantes não foram editados, ou seja, transcrevemos da maneira com que eles registraram nos questionários.

${ }^{3}$ As palavras grifadas nesses exemplos destacam os elementos que consideramos por 'Unidades de sentido' e que são representativos das ações dos estudantes investigados, naquilo que se refere ao seu pensar sobre os pensamentos relativos ao saber que sei e ao saber que aprendi. Para as descrições explicitadas no quadro 2, reescrevemos todas as 'ações' na forma verbal infinitiva.

${ }^{4}$ Apesar de os autores de origem denominarem tais relações com o saber por Relação epistêmica, pessoal e social, nós as assumimos por categorias a priori e as estabelecemos por Dimensões, ou seja, assumimos por sinônimas tais denominações.
} 
No gráfico 1 temos a quantificação de todos os depoimentos categorizados, sendo que $51 \%$ foram epistêmicos, $25 \%$ pessoais e $24 \%$ sociais.

No quadro 3, na coluna 2, acomodados em cada uma das categorias a priori epistêmica, pessoal e social - os elementos que assumimos por Unidades de sentido - referentes aos registros, que nos levaram a interpretá-los como pertinentes àquela categoria e que, segundo nossa visão, são representativos das percepções expostas pelos engenheiros em formação, a respeito de seu saber e de seu aprender. Na coluna 3 , temos os 45 registros codificados, alocados, assim como na coluna 4 as quantidades evidenciadas em relação às Unidades de sentido e às categorias a priori epistêmica, pessoal e social. Como pode ser observado, um único registro foi fragmentado em dois - R36a e R36b - pelo fato de se acomodar em duas das categorias previamente assumidas, respectivamente, epistêmica e pessoal.

Quadro 3 - Acomodação das Unidades de sentido

\begin{tabular}{|c|c|c|c|}
\hline Dimensões & $\begin{array}{c}\text { Unidades de } \\
\text { sentido }\end{array}$ & Registros dos estudantes & Quantidades \\
\hline \multirow[t]{11}{*}{ Epistêmica } & Estudar & $\mathrm{R} 2$ & 1 \\
\hline & Refletir & R4, R20, R25, R31, R36a, R40 & 6 \\
\hline & Aplicar/Praticar & $R 6, R 11, R 12, R 13, R 14, R 15, R 28, R 41$ & 8 \\
\hline & Explicar & $\mathrm{R} 42$ & 1 \\
\hline & Associar/Relacionar & $\mathrm{R} 10, \mathrm{R} 45$ & 2 \\
\hline & Resolver & $\mathrm{R} 27$ & 1 \\
\hline & Dialogar & R37 & 1 \\
\hline & Vivenciar & R38 & 1 \\
\hline & Pensar & R43 & 1 \\
\hline & Reproduzir & R44 & 1 \\
\hline & Conhecer & $\mathrm{R} 21, \mathrm{R} 22$ & 2 \\
\hline \multirow[t]{8}{*}{ Pessoal } & Esforçar & R3 & 1 \\
\hline & Aprender & R5 & 1 \\
\hline & Memorizar/Sentir & $\mathrm{R} 16$ & 1 \\
\hline & Habituar & $\mathrm{R} 17$ & 1 \\
\hline & Duvidar & R19, R23, R24 & 3 \\
\hline & Aplicar/Praticar & $\mathrm{R} 26, \mathrm{R} 32$ & 2 \\
\hline & Refletir & R34, R36b & 2 \\
\hline & Dialogar & R37 & 1 \\
\hline \multirow[t]{5}{*}{ Social } & Refletir & $\mathrm{R} 1$ & 1 \\
\hline & Aplicar/Praticar & R15, R33, R39 & 3 \\
\hline & Explicar & $R 7, R 8, R 9, R 18, R 29, R 30$ & 6 \\
\hline & Conhecer & $\mathrm{R} 28$ & 1 \\
\hline & Ensinar & R35 & 1 \\
\hline
\end{tabular}

Fonte: elaborado pelos autores.

O quadro 3 proporciona visualizar a totalidade dos registros dos estudantes, distribuídos nas Unidades de sentido, representados pelos verbos, bem como sua alocação em termos das Dimensões epistêmicas, pessoais e sociais. As Unidades de sentido com maior incidência estão na categoria que destaca a relação com o saber 
na Dimensão epistêmica e traz por ações aplicar/praticar e refletir, linhas 3 e 2, respectivamente, quando alocamos os registros $(R)$. Outra linha que se destaca - na Dimensão social - está representada pelo verbo 'explicar'.

No quadro 4, procurando esclarecer a respeito dos nossos movimentos interpretativos, trazemos na coluna 1, destacadas, as categorias assumidas das dimensões com o saber; na coluna 2, 'exemplos' dos registros dos estudantes; na coluna 3, as Unidades de sentido por nós assumidas, levando em consideração as ações explicitadas pelos estudantes (nos registros) e transcritas para o infinitivo; por fim, na coluna 4, os verbos (também no infinitivo, por nós descritos) que representam o que eles 'comunicam que pensaram', ou seja, 'representam o pensar sobre o próprio pensar'.

Quadro 4 - Unidades de sentido e verbos provenientes de exemplos de explicitações

\begin{tabular}{|c|c|c|c|}
\hline $\begin{array}{l}\text { Relações } \\
\text { com o saber }\end{array}$ & Registros dos estudantes & $\begin{array}{l}\text { Unidades de } \\
\text { sentido }\end{array}$ & Verbos \\
\hline \multirow[t]{3}{*}{ Epistêmica } & $\begin{array}{l}\text { (E2-R6) Quando a maior parte dos exercícios fica* fácil e } \\
\text { quando a parte teórica está clara em minha cabeça. }\end{array}$ & Aplicar & Ficar; estar \\
\hline & $\begin{array}{l}\text { (E5-R14) Sei que eu aprendo quando vou à aula, depois } \\
\text { leio no livro o que foi dado fazendo anotações e prática de } \\
\text { exercícios. }\end{array}$ & Aplicar / Praticar & Saber; aprender; ler; fazer. \\
\hline & $\begin{array}{l}\text { (E5-R15) Sei que aprendi quando consigo resolver exercício, } \\
\text { sozinha. Quando consigo relacionar o que está escrito nos } \\
\text { livros com o mundo e as coisas que acontecem nele, por } \\
\text { entender o porquê das coisas serem como são e os processos } \\
\text { que envolvem. }\end{array}$ & Aplicar / Praticar & $\begin{array}{l}\text { Aprender; saber; conse- } \\
\text { guir; resolver; relacionar; } \\
\text { acontecer; entender; ser; } \\
\text { envolver. }\end{array}$ \\
\hline \multirow[t]{3}{*}{ Pessoal } & $\begin{array}{l}\text { (E6-R17) Para aprender algo, deve-se primeiramente } \\
\text { almejar o conhecimento que se deseja obter, após deve-se } \\
\text { estudar periodicamente voltando total atenção à matéria } \\
\text { no momento de estudo; por fim, só aprende com o hábito } \\
\text { de estudo. }\end{array}$ & Habituar & $\begin{array}{l}\text { Aprender; dever; almejar; } \\
\text { desejar; obter; estar; estu- } \\
\text { dar; voltar. }\end{array}$ \\
\hline & $\begin{array}{l}\text { (E9-R26) Tem um provérbio chinês que gosto muito e me diz } \\
\text { exatamente a melhor forma de aprender sobre determinado } \\
\text { assunto 'escuto e esqueço, vejo e lembro, faço e aprendo; } \\
\text { a melhor forma de se aprender é praticar'. }\end{array}$ & Aplicar / Praticar & $\begin{array}{l}\text { Gostar; dizer; aprender; } \\
\text { escutar; esquecer; ver; } \\
\text { lembrar; fazer; praticar. }\end{array}$ \\
\hline & $\begin{array}{l}\text { (E12-R35) Eu aprendo quando sou forçada a aprender para } \\
\text { ensinar os outros, pois, e quando faço uma reflexão acerca do } \\
\text { que está sendo apresentado a mim, de forma crítica, quando } \\
\text { penso nas possíveis dúvidas e questionamentos que podem } \\
\text { ser feitos a mim. }\end{array}$ & Ensinar / Refletir & $\begin{array}{l}\text { Aprender; ser; forçar; } \\
\text { ensinar; fazer; pensar. }\end{array}$ \\
\hline \multirow[t]{3}{*}{ Social } & $\begin{array}{l}\text { (E3-R9) Quando eu percebo que sei explicar a teoria e } \\
\text { lembrar dela, dando mais certeza para falar sobre aquilo. } \\
\text { Além disso, eu posso explicar. }\end{array}$ & Explicar & $\begin{array}{l}\text { Perceber; ser; explicar; } \\
\text { lembrar; falar; poder. }\end{array}$ \\
\hline & $\begin{array}{l}\text { (E6-R18) Quando se sabe bem a matéria estudada a pessoa } \\
\text { consegue transmitir esse conhecimento a outro de forma } \\
\text { muito mais fácil, aquele que não detém o conhecimento } \\
\text { necessário. }\end{array}$ & Explicar & $\begin{array}{l}\text { Saber; estudar; conseguir; } \\
\text { transmitir; deter. }\end{array}$ \\
\hline & $\begin{array}{l}\text { (E10-R30) Sei que aprendo quando eu consigo transmitiro } \\
\text { meu conhecimento para alguém que não sabe sobre o assunto, } \\
\text { quando sei falar sobre o assunto com convicção e com uma } \\
\text { base teórica por trás, também quando consigo executar um } \\
\text { problema sobre o assunto envolvido. }\end{array}$ & Explicar & $\begin{array}{l}\text { Aprender; conseguir; } \\
\text { transmitir; saber; falar; } \\
\text { executar; envolver. }\end{array}$ \\
\hline
\end{tabular}

*Neste quadro os verbos conjugados e que foram deslocados para a quarta coluna na forma infinitiva estão destacados em negrito.

Fonte: elaborado pelos autores. 
Observamos que nos registros dos estudantes sobre as duas questões propostas, identifica-se um conjunto de verbos utilizados para manifestar seus pensamentos. Alguns destes verbos parecem evidenciar sua relação com as Unidades de sentido e as categorias a priori, epistêmica, pessoal e social, bem como características presentes nestes registros. Segundo Arruda e Passos (2017, p. 99), os sujeitos demonstram relações epistêmicas quando utilizam "[...] discursos puramente intelectuais ou cognitivos expressando-se, em geral, por meio de oposições do tipo sei/não sei, conheço/não conheço, compreendo/não compreendo etc." Observando o quadro 4, anteriormente descrito, notamos que os estudantes manifestaram pensamentos epistêmicos, utilizando verbos relacionados com as expressões apontadas por Arruda e Passos (2017), embora surjam alguns verbos que, a princípio, não estariam relacionados com esse caráter cognitivo e epistêmico, mas que dentro do registro completo atribuem sentido à frase expressada, sendo possível caracterizar aquele registro com a relação epistêmica e a Unidade de sentido a ele atribuída. Da mesma forma, uma análise proposital pode ser feita considerando as relações pessoais e sociais, e as Unidades de sentido e os verbos a elas associados.

Procurando representar essas interpretações realizadas e a evidenciação desses vínculos encontrados, projetamos três gráficos que trazemos na sequência, seguidos de comentários explicativos e conclusivos.

Gráfico 2 - Unidades de sentido na Dimensão epistêmica

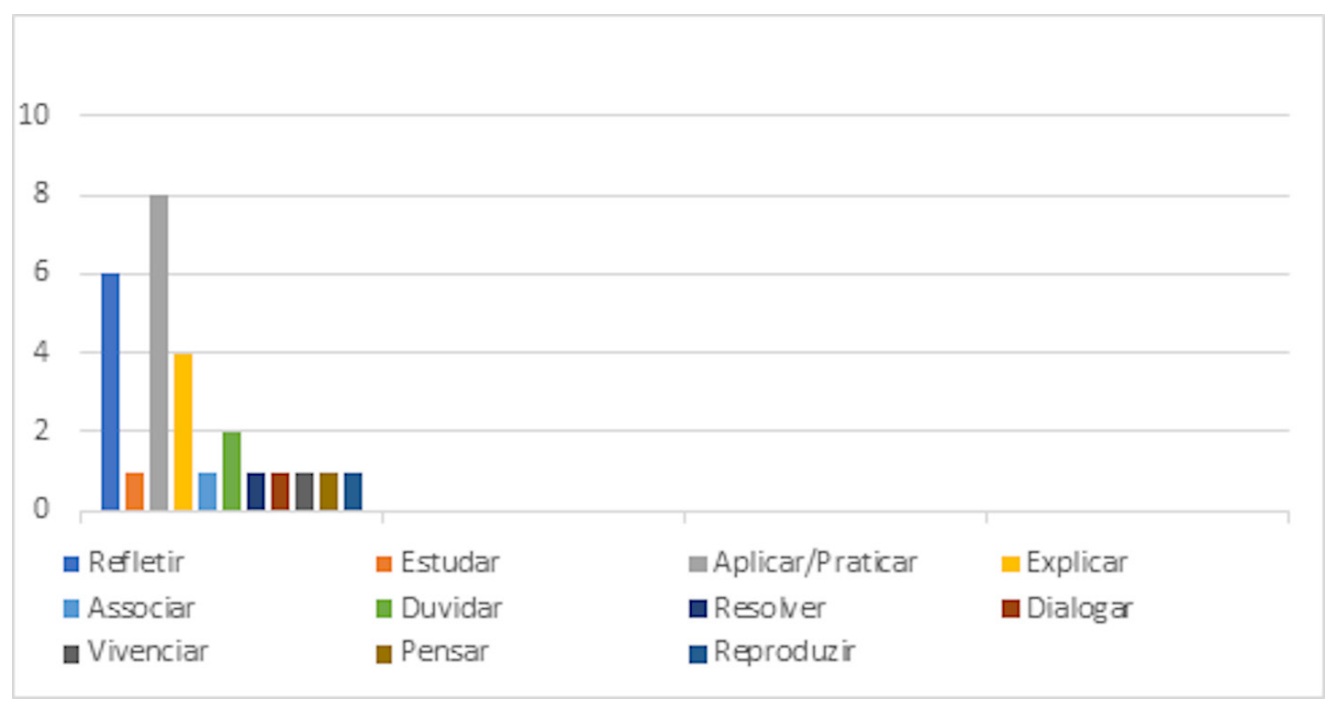

Fonte: elaborado pelos autores.

No gráfico 2 estão expostas 11 Unidades de sentido obtidas a partir do procedimento analítico, sendo que o maior número de trechos dos registros dos estudantes foi alocado nas Unidades Aplicar/Praticar, Refletir e Explicar, com oito, seis e quatro trechos dos registros, respectivamente. Podemos inferir que para esse grupo de estudantes suas percepções a respeito do saber e do aprender, relacionadas ao caráter epistêmico, possuem sentido na aplicação e na prática do saber e do aprender Física, assim como um processo de reflexão e a capacidade de explicar os conteúdos aprendidos. 


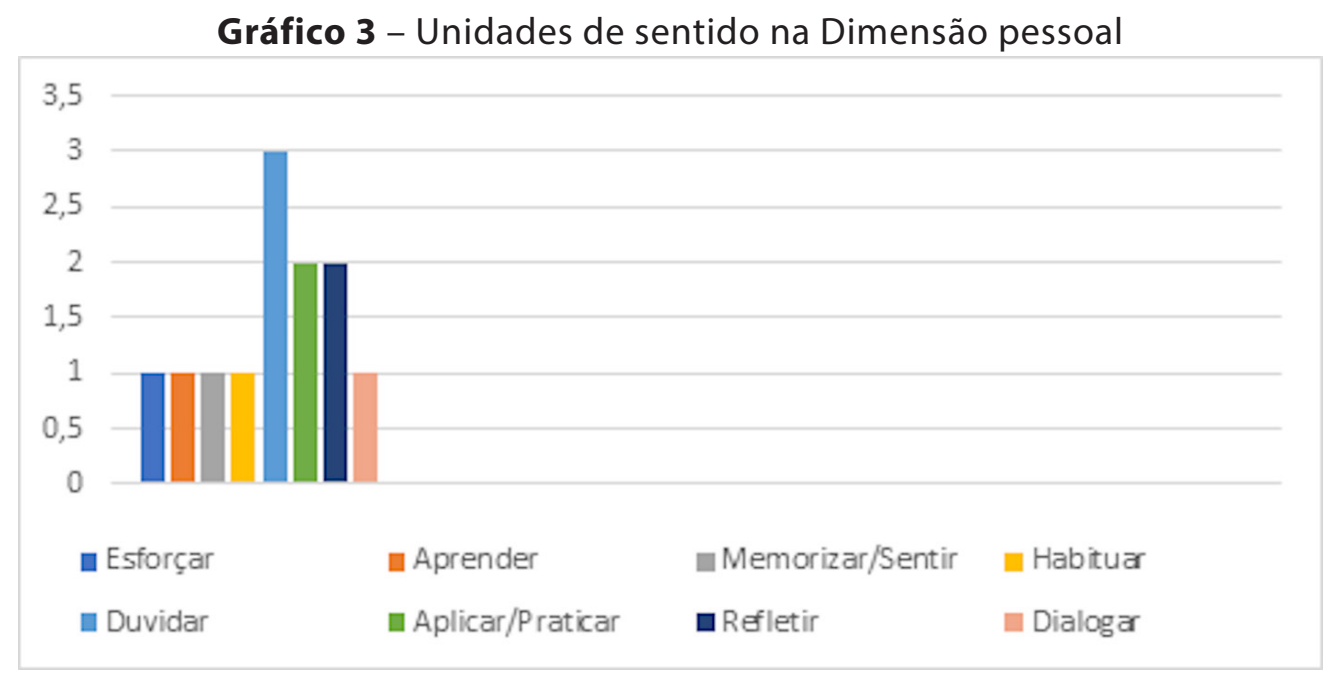

Fonte: elaborado pelos autores.

Para a Dimensão pessoal com o saber foram evidenciadas oito Unidades de sentido, sendo elas representadas no gráfico 3, anterior. Nessa categoria encontramos que o maior número de trechos dos registros refere-se às Unidades Duvidar, Aplicar/ Praticar e Refletir. Novamente observamos a presença das Unidades Aplicar/Praticar e Refletir, acrescidas da Unidade Duvidar, em que para esse grupo de estudantes o saber e o aprender Física possuía relação com eximir as dúvidas relacionadas aos conteúdos de Física. Também se observa que o sentido de aplicação e prática dos conteúdos da disciplina, assim como reflexão sobre esses conteúdos, estão presentes nos registros dos estudantes.

Gráfico 4 - Unidades de sentido na Dimensão social

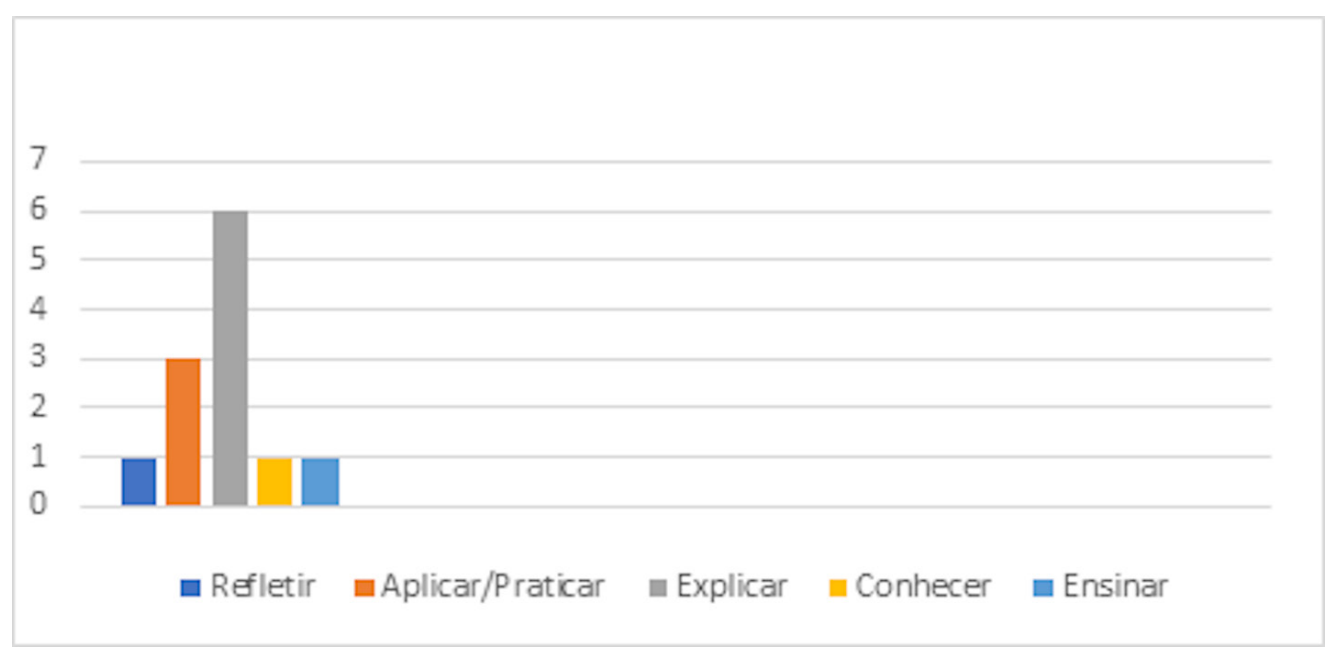

Fonte: elaborado pelos autores.

No gráfico 4 tem-se as Unidades de sentido evidenciadas na Dimensão social com o saber. Observa-se que as Unidades que apresentam maior número de registros são as Unidades Explicar e Aplicar/Praticar, com seis e três trechos de registros, respectivamente. As outras Unidades referem-se a Refletir, Ensinar e Conhecer com um registro do estudante, cada Unidade alocada nesta categoria. Ao todo, nesta categoria encontramos cinco Unidades de sentido. 
Com os procedimentos analíticos assumidos e aplicados pudemos categorizar os registros dos estudantes em termos das relações epistêmicas, pessoais e sociais com o saber, bem como identificar Unidades de sentido associadas a esses registros e relacioná-las com as categorias epistêmicas, pessoais e sociais. A quantidade de trechos de registros dos estudantes com maior incidência está relacionada à relação epistêmica com o saber, seguido da relação pessoal e, depois, da relação social com o saber. A maior quantidade de Unidades de sentido evidenciadas nos registros refere-se à categoria epistêmica, novamente seguida pela pessoal e social. Foi possível identificar verbos que caracterizassem as percepções dos estudantes em termos das relações epistêmicas, pessoais e sociais e as Unidades de sentido evidenciadas. Os verbos mais presentes são: aplicar/praticar, refletir, explicar e duvidar (epistemicamente); duvidar, aplicar/praticar, refletir (pessoalmente); aplicar/praticar e explicar (socialmente). A única Unidade de sentido presente em todas as dimensões com maior ênfase foi aplicar/praticar.

$\mathrm{Na}$ continuidade, encerramos nosso artigo trazendo algumas considerações conclusivas proporcionadas por este movimento investigativo e analítico.

\section{Considerações finais}

A partir dos resultados podemos observar que as percepções dos estudantes a respeito do saber e do aprender Física estão relacionadas, principalmente, com a aplicação e a prática, a reflexão e as dúvidas referentes aos conteúdos estudados na disciplina. Estas percepções evidenciaram-se a partir das reflexões metacognitivas proporcionadas pela atividade proposta.

A análise dos resultados também proporcionou identificar que as percepções dos estudantes nesse movimento reflexivo situam-se na relação epistêmica com o saber, seguido da relação pessoal e social. Outro ponto observado, a partir dos procedimentos analíticos, é que a Unidade de sentido Aplicar/Praticar apresenta-se nas três categorias de análise, apontando que não somente no caráter epistêmico a ideia da aplicação e da prática está presente nas percepções dos estudantes, mas também em suas Dimensões pessoais e sociais com o saber. De maneira similar, os verbos mais presentes nas Unidades de sentido representadas pelos verbos aplicar/praticar, refletir e explicar evidenciam que os processos metacognitivos não envolvem somente aspectos epistêmicos, mas também pessoais e sociais corroborando as pesquisas de Corrêa, Passos e Arruda (2018) e Efklides (2008). Ainda são pouco expressivos os estudos que envolvem o nível social dos processos metacognitivos (ROSA et al., 2021), indicando a necessidade de investigações futuras.

Foi possível também identificar dois verbos que não foram explicitados em suas relações com as categorias de análise e as Unidades de sentido presentes nos registros dos estudantes: saber e aprender, e que aparecem com maior incidência nos registros. Este resultado pode estar relacionado às questões dissertativas propostas aos estudantes para responderem. Pela incidência observada e pela não consideração de tais colocações como Unidades de sentido, nosso movimento foi o de destacar em qual categoria eles se apresentavam com maior regularidade (quando focamos os fragmentos em que estavam presentes). O verbo saber mostrou-se associado, 
principalmente, à relação epistêmica e o verbo aprender às relações pessoais e sociais. A caracterização a partir dos verbos proporcionou observar como as percepções dos estudantes são manifestadas e os sentidos atribuídos pelos mesmos a respeito do saber e aprender Física dentro de Dimensões epistêmicas, pessoais e sociais.

De maneira geral, a atividade proposta possibilitou aos estudantes uma reflexão a respeito do próprio aprendizado. A reflexão é tida como fundamental para os processos metacognitivos, assim como essencial para o desenvolvimento de aprendizes eficazes (ERTMER; NEWBY, 1996). Além disso, a compreensão da natureza do aprender e conhecer, segundo Fonseca (2018), é o coração da metacognição.

Por fim, concluímos que esta proposta investigativa proporcionou resultados iniciais que podem abrir caminhos para estudos posteriores, a fim de compreender melhor as percepções dos estudantes a respeito do saber e do aprender Física, assim como possibilitar a evidenciação e a elaboração de novos elementos, a partir de momentos reflexivos e metacognitivos para o desenvolvimento de atividades que foquem no ensino e na aprendizagem da Física, não somente para cursos de Engenharia, mas para outros cursos em que as disciplinas da área de Física estão presentes.

\section{Agradecimentos}

Keila Padilha de Oliveira Camargo de Lima agradece o apoio da Coordenação de Aperfeiçoamento de Pessoal de Nível Superior (CAPES) por meio de bolsa de mestrado. Marinez Meneghello Passos agradece apoio do Conselho Nacional de Desenvolvimento Científico e Tecnológico (CNPq) a partir de projeto vinculado à Bolsa de Produtividade em Pesquisa. João Paulo Camargo de Lima agradece apoio do CNPq mediante bolsa de Pós-doutorado Sênior.

\section{Referências}

ANDRETTA, I.; SILVA, J. G.; SUSIN, N.; FREIRE, S. D. Metacognição e aprendizagem: como se relacionam? Psico, Porto Alegre, v. 41, p. 7-13, 2010. Disponível em:_https://revistaseletronicas. pucrs.br/ojs/index.php/revistapsico/article/view/3879. Acesso em: 11 out. 2021.

ARRUDA, S. M.; BENICIO, M. A.; PASSOS, M. M. Um instrumento para a análise das percepções/ ações de estudantes em sala de aula. Revista Brasileira de Ensino de Ciência e Tecnologia, Ponta Grossa, v. 10, n. 2, p. 325-345, 2017. DOI: https://doi.org/g2ft.

ARRUDA, S. M.; LIMA, J. P. C.; PASSOS, M. M. Um novo instrumento para análise da ação do professor em sala de aula. Revista Brasileira de Pesquisa em Educação em Ciências, Belo Horizonte, v. 11, n. 2, p. 139-160, 2011. Disponível em: https://periodicos.ufmg.br/index.php/rbpec/article/ view/4200. Acesso em: 11 out. 2021.

ARRUDA, S. M.; PASSOS, M. M. Instrumentos para a análise da relação com o saber em sala de aula. Revista de Produtos Educacionais e Pesquisas em Ensino, Cornélio Procópio, v. 1, n. 2, p. 95 115, 2017. Disponível em: http://seer.uenp.edu.br/index.php/reppe/article/view/1213. Acesso em: 11 out. 2021.

AVARGIL, S.; LAVI, R.; DORI, Y. J. Students' metacognition and metacognitive strategies in science education. In: DORI, Y. J.; MEVARECH, Z. R.; BAKER, D. R. (ed.). Cognition, metacognition, and culture in STEM education. Dordrecht: Springer, 2018. p. 33-64.

BAKER, E. Metacognition. In: PETERSON, P.; BAKER, E.; MCGAW, B. (org.). International encyclopedia of education. 3. ed. Oxford: Elsevier, 2010. p. 204-210. 
BARDIN, L. Análise de conteúdo. São Paulo: Edições 70, 2011.

CHARLOT, B. Da relação com o saber: elementos para uma teoria. Porto Alegre: Artmed, 2000.

CHARLOT, B. Os jovens e o saber: perspectivas mundiais. Porto Alegre: Artmed, 2001.

CHARLOT, B. Relação com o saber, formação de professores e globalização: questões para a educação hoje. Porto Alegre: Artmed, 2005.

CORRÊA, N. N. G.; PASSOS, M. M.; ARRUDA, S. M. Metacognição e as relações com o saber. Ciência \& Educação, Bauru, v. 24, p. 517-534, 2018. DOI: https://doi.org/ggjf7z.

CORRÊA, N. N. G.; PASSOS, M. M.; ARRUDA, S. M.; ROSA C. T. W. Entendendo a metacognição e sua influência conativa para a aprendizagem. In: CORREA, H. E. R.; FIORUCCI, R.; PAIXÃO, S. V. (org.). Educação (integral) para o século XXI: cognição, aprendizagens e diversidades. Bauru: Gradus, 2021. p. 119-140.

CORRÊA, N. N. G; PASSOS, M. M.; CORRÊA, H. E. R.; ARRUDA, S. M. Estudo exploratório sobre o uso da palavra "metacognição" em artigos publicados em periódicos brasileiros do ensino de ciências e matemática de 2007 a 2017. Caderno Brasileiro de Ensino de Física, Florianópolis, v. 37, n. 1, p. 6-26, 2020. DOI: https://doi.org/g2fv.

EFKLIDES, A. Metacognition: defining its facets and levels of functioning in relation to selfregulation and co-regulation. European Psychologist, v. 13, n. 4, p. 277-287, 2008. DOI: https://doi. org/bgbt9q.

ERTMER, P. A.; NEWBY, T. J. The expert learner: strategic, self-regulated, and reflective. Instructional Science, Dordrecht, v. 24, n. 1, p. 1-24, 1996. DOI: https://doi.org/drhdd3.

FLAVELL, J. H. Metacognition and cognitive monitoring: a new area of cognitive-developmental inquiry. American Psychologist, Washington, v. 34, n. 10, p. 906-910, 1979. DOI: https://doi.org/cg33qs.

FLAVELL, J. H. Metacognitive aspects of problem solving. In: RESNICK, L. B. (org.). The nature of intelligence. Hillsdale: Lawrence Erlbaum, 1976. p. 231-236.

FLICK, U. Introdução à pesquisa qualitativa. 3. ed. Porto Alegre: Artmed, 2009.

FONSECA, V. Desenvolvimento cognitivo e processo de ensino-aprendizagem: abordagem psicopedagógica à luz de Vygotsky. Petrópolis: Vozes, 2018.

ILLERIS, K. Uma compreensão abrangente sobre a aprendizagem humana. In: ILLERIS, K. (org.). Teorias contemporâneas da aprendizagem. Porto Alegre: Penso, 2013. p. 15-30.

LIMA, J. P. C.; PASSOS, M. M.; ARRUDA, S. M.; DÖHL, V. V. Aprofundando a compreensão da aprendizagem docente. Ciência \& Educação, Bauru, v. 21, n. 4, p. 869-891, 2015. DOI: https://doi. org/g2f4.

PASSOS, M. M.; CORRÊA, N. G.; ARRUDA, S. M. Perfil metacognitivo (parte I): uma proposta de instrumento de análise. Investigações em Ensino de Ciências, Porto Alegre, v. 22, p. 176-191, 2017. DOI: https://doi.org/g2f5.

PETERSON, P.; BAKER, E.; MCGAW, B. (ed.). International encyclopedia of education. 3. ed. Dordrecht: Elsevier, 2010.

ROSA, C. T. W.; CORRÊA, N. N. G.; PASSOS, M. M.; ARRUDA, S. M. Metacognição e seus 50 anos: cenários e perspectivas para o ensino de ciências. Revista Brasileira de Ensino de Ciências e Matemática, Passo Fundo, v. 4, n. 1, p. 267-291, 2021. DOI: https://doi.org/g2f6.

ROSA, C. T. W.; GHIGGI, C. M. Resolução de problemas em física envolvendo estratégias metacognitivas: análise de propostas didáticas. Investigações em Ensino de Ciências, Porto Alegre, v. 23, n. 3, p. 31-59, 2018. DOI: https://doi.org/gf3xmv. 
ROSA, C. T. W.; RIBEIRO, C. A. G.; ROSA, A. B. Habilidades metacognitivas envolvidas na resolução de problemas em física: investigando estudantes com expertise. Amazônia, Belém, v. 14, n. 29, p. 143-160, 2018. DOI: https://doi.org/ggjpx9.

ROSA, C. T. W.; VILLAGRÁ, J. A. M. Metacognição e ensino de física: revisão de pesquisas associadas a intervenções didáticas. Revista Brasileira de Pesquisa em Educação em Ciências, Belo Horizonte, v. 18, n. 2, p. 581-608, 2018. DOI: https://doi.org/ggk544.

VEENMAN, M. V. J. Metacognition in science education: definitions, constituents, and their intricate relation with cognition. In: ZOHAR, A.; DORI, Y. J. (ed.). Metacognition in science education: trends in current research. Cham, Switzerland: Springer, 2012. p. 21-36.

ZOHAR, A.; BARZILAI, S. A review of research on metacognition in science education: current and future directions. Studies in Science Education, London, v. 49, p. 121-169, 2013. DOI: https://doi. org/ghd3w6. 